\title{
Article
}

\section{Testing of Silicon Rubber/Montmorillonite Nanocomposite for Mechanical and Tribological Performance}

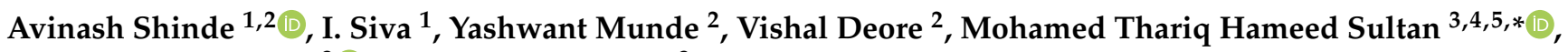 \\ Ain Umaira Md Shah ${ }^{3}$ (D) and Faizal Mustapha ${ }^{3}$ \\ 1 Center for Composite Materials, Kalasalingam Academy of Research and Education, \\ Anand Nagar 6261286, TN, India; avinash.shinde@cumminscollege.in (A.S.); isiva@klu.ac.in (I.S.) \\ 2 Department of Mechanical Engineering, Cummins College of Engineering for Women, \\ Pune 411052, MH, India; Yashwant.Munde@cumminscollege.in (Y.M.); \\ vishal.deore@cumminscollege.in (V.D.) \\ 3 Department of Aerospace Engineering, Faculty of Engineering, Universiti Putra Malaysia, \\ Serdang 43400 UPM, Selangor Darul Ehsan, Malaysia; ainumaira91@gmail.com (A.U.M.S.); \\ faizalms@upm.edu.my (F.M.) \\ 4 Laboratory of Biocomposite Technology, Institute of Tropical Forestry and Forest Products (INTROP), \\ Universiti Putra Malaysia, Serdang 43400 UPM, Selangor Darul Ehsan, Malaysia \\ 5 Aerospace Malaysia Innovation Centre (944751-A), Prime Minister's Department, MIGHT Partnership Hub, \\ Jalan Impact, Cyberjaya 63000, Selangor Darul Ehsan, Malaysia \\ * Correspondence: thariq@upm.edu.my
}

check for updates

Citation: Shinde, A.; Siva, I.; Munde, Y.; Deore, V.; Hameed Sultan, M.T.; Md Shah, A.U.; Mustapha, F. Testing of Silicon Rubber/Montmorillonite Nanocomposite for Mechanical and Tribological Performance. Nanomaterials 2021, 11, 3050. https://doi.org/10.3390/ nano11113050

Academic Editor: Csaba Balázsi

Received: 7 May 2021

Accepted: 1 June 2021

Published: 12 November 2021

Publisher's Note: MDPI stays neutral with regard to jurisdictional claims in published maps and institutional affiliations.

Copyright: (c) 2021 by the authors. Licensee MDPI, Basel, Switzerland. This article is an open access article distributed under the terms and conditions of the Creative Commons Attribution (CC BY) license (https:/ / creativecommons.org/licenses/by/ $4.0 /)$.

\begin{abstract}
Nanocomposite made by blending nano-montmorillonite (MMT) and Silicon Rubber (SR) for mechanical and tribological performance is explored in this work. Different configurations of MMT/SR nanocomposite, with 0, 0.5, 2 and $5 \mathrm{wt} \%$ of MMT are manufactured by two roll mixing methods. Noticeable improvement in the mechanical and tribological performance is observed, which is also justified by a morphological study of fractured and wear surfaces through SEM. Two percent of MMT loading is found to be the optimum content that shows excellent performance compared to other compositions. The performance improvement can be linked to the good interfacial interaction between the MMT and SR. Statistical modeling through ANOVA is carried out for tribological performance, which reveals the influence of load on the coefficient of friction (COF) and the influence of sliding distance on the wear rate.
\end{abstract}

Keywords: silicon rubber; montmorillonite (MMT); sliding wear; mechanical properties; nanocomposites

\section{Introduction}

Synthetic elastomers like silicone rubber (SR) are commonly found in application in industries such as aerospace, medical, and electronics. Owing to their excellent environmental inertness, thermal stability, and insulating properties [1,2], most sectors prefer SR. Silicon rubber properties can be radically improved by adding nanofillers like carbon black (CB), carbon nanotube (CNT), graphite, nano $\mathrm{C}_{\mathrm{e}} \mathrm{O}_{2}[3,4]$. Similar works can be found in literature that show the influence of graphene oxide addition on resistivity and dielectric constant [5], thermal stability with the function of iron oxide and CNT filling [6], and tribological study [7] of various nanocomposites performed on the SR composite. All of these studies have revealed the usefulness of SR for different engineering applications.

The utility of SR for different applications can be improved by a deep analysis of its mechanical and tribological properties, among others. The mechanical and wear characteristic of rubber components can be one essential factor when deciding its candidature for a particular application. Adding graphene and nano- $\mathrm{C}_{\mathrm{e}} \mathrm{O}_{2}$ as a filler in SR showed a decrease in the COF [4]. Reinforcement with $\mathrm{CB}$ enhanced the mechanical and tribological properties [8]. Graphite nanoplatelets improved the mechanical and abrasion resistance properties of the styrene-butadiene rubber [9]. The kinetic COF of the tubular rubber seal 
decreases with an increasing sliding velocity and reduces the loading level [10]. The wear properties of natural rubber and styrene-butadiene rubber were tested against different rocks as friction material and found to be improved [11]. The enhancement of mechanical, wear, and dielectric properties due to the addition of the exfoliated graphite in silicon rubber was investigated. The COF was observed to reduce with an increase in the wear rate and load. Simultaneously, the specific wear rate reduced, similar to COF, with graphite content but increased with an increase in load. The sliding velocity had a similar effect on both the COF and the wear rate, and it increased with an increase in the sliding velocity. The author correlated this improvement with good bonding between the matrix and the filler [12]. Ruben Sanchez-Hidalgo [13] demonstrated that if we can control the structure, the chemical composition, and the morphology of graphene material, the property of the SR can be tailored. Solution and flocculation processes were used for the preparation of the graphene silicon composite. The wear and mechanical characteristics depended on the reinforcement and agglomeration of the graphene [14]. The sonication process for processing polyacrylamide (PMA) reinforced with clay nanoparticles was used, and the effect of the sonication time and frequency was investigated. The rheological properties and nanoparticles dispersion were found to improve with an increase in the frequency [15].

Very few researchers have explored the capability of montmorillonite (MMT) for tribological application as a filler in polymers [16]. With increases in the concentration of MMT, the COF was found to decrease due to its lubricating behaviour. Sodium-montmorillonite (Na-MMT) nanoparticles were added to polyethersulfone (PES)/ polytetrafluoroethylene (PTFE) to understand the thermal, mechanical, and tribological properties. All properties showed considerable improvement. The reduction in COF was observed with a rise in the normal load for Na-MMT/PES/PTFE composites. The author attributed this to the layered structure of the Na-MMT nanoparticles. A precisely opposite behaviour was shown by the Na-MMT/PES/PTFE composite. The authors observed that the response of both compositions to the sliding velocity was exactly contrary for the normal load. The weight, $\mathrm{COF}$, and wear rate of the composite can be decreased with the addition of MMT in the matrix $[16,17]$. The effect of the grain size and distribution of Ag2s nanoparticles on the mechanical and tribological performance was studied. The improvement in the tribological performance was attributed to good mechanical properties and an ability to form a protective tribofilm [18]. Tribological properties of the graphene reinforced ceramic showed improvement because of the formation of a protective transfer layer, which acted as a lubricant between the contacting surfaces $[19,20]$.

SR has wider suitability in aerospace, automotive, electrical, and electronic industries. There is no work reported on the effectiveness of MMT/silicon rubber nanocomposites for tribological applications to the best of the authors' knowledge. The objective of this work is to investigate the mechanical and tribological behaviour of the silicon rubber-MMT nanocomposites. In this work, the weight percentage of MMT is set at 0.5, 2 and 5\%. Pin-on-disc testing experiments are performed with different loading, sliding velocity, and sliding distance. The ANOVA experimental design technique is used for designing experiments and statistical modeling. Weight loss and friction force are calculated and used for the calculation of the specific wear rate. Manufacturing, testing, and results are discussed in detail in the following sections.

\section{Materials and Methods}

\subsection{Material Details}

SR with SH5060U grade was procured from Krupa Chemicals, Pune, India. Montmorillonite (MMT) was supplied by Ad-Nano Technologies Private Limited, Shimoga, India. The material properties as specified by the supplier in the datasheet are listed in Table 1 . The curing agent used was Dicumyl Peroxide of $40 \%$ purity procured from Krupa Chemicals and used in the proportion as given in Table 2 with SR. 
Table 1. Properties of Material.

\begin{tabular}{ccc}
\hline Type/Grade & Silicon Rubber (SH5060 U) & MMT \\
\hline Specific Gravity (g/cc) & 1.15 & 1.98 \\
Tensile Strength, Ultimate & 5 & 101 \\
(MPa) & 500 & 8 \\
Elongation (\%) & $50(\mathrm{~A})$ & $83(\mathrm{D})$ \\
Hardness, Shore & - & 100 \\
Particle size (nm) &
\end{tabular}

Table 2. Nanocomposite filler formulations (in weight percent, remaining is SR).

\begin{tabular}{ccccc}
\hline Type/Grade & SR1 & SR2 & SR3 & SR4 \\
\hline MMT & 0 & 0.5 & 2 & 5 \\
DCP & 2 & 2 & 2 & 2 \\
\hline
\end{tabular}

\subsection{Preparation of Silicon Rubber-Nanoclay Composites}

The schematic representation of SR-MMT manufacturing is shown in Figure 1. SR with SH5060U grade and peroxide-based curing agent such as Dicumyl Peroxide (DCP) of $40 \%$ purity were compounded with different weight concentrations of nanoclay, viz., $0,0.5,2,5 \%$ and are hereafter referred to as SR1, SR2, SR3, and SR4. The compounding formulation is listed in Table 2. The mixing was carried out for approximately 40 min on a two roll mill machine. The compound was cured in a SANTEC compression moulding machine (Santech Industries, Delhi, India) of 30 ton capacity. The temperature, pressure, and curing time were maintained at 170 degrees, 50 bar and $5 \mathrm{~min}$, respectively; followed by the post-curing at 200 degrees for $4 \mathrm{~h}$ in a hot air oven (Make: Athena Technology, Model: ATAO-3 S/G).
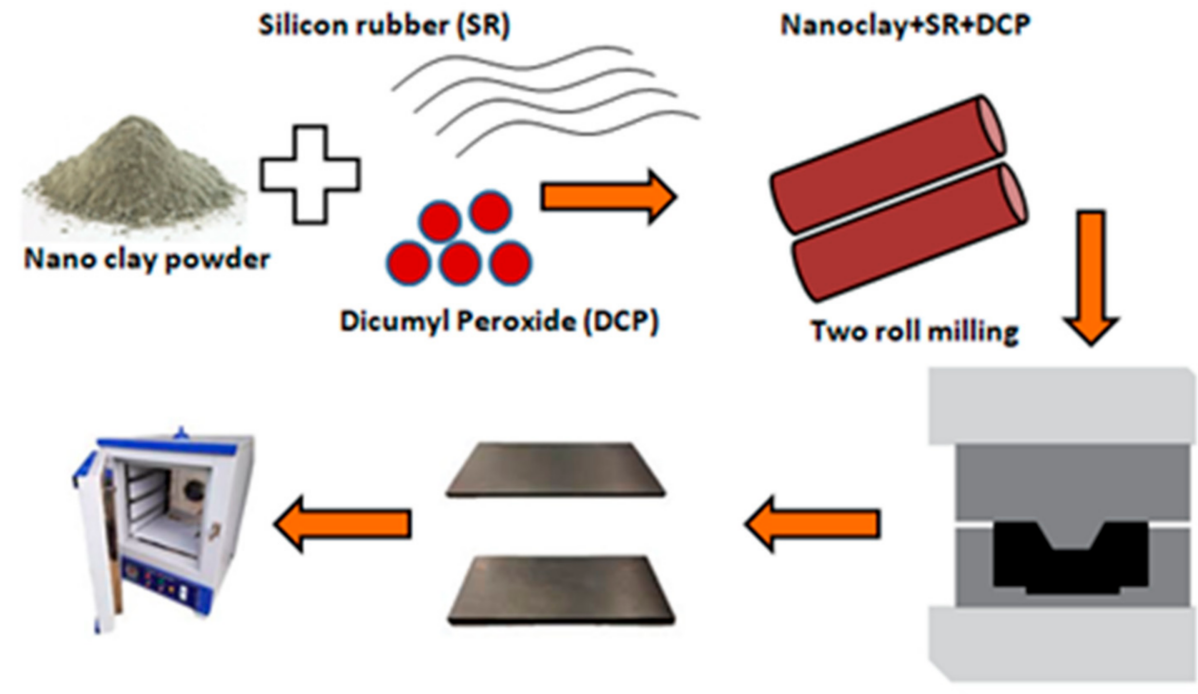

Post Curing in hot air oven

SR plates

Compression molding

Figure 1. Schematic representation of SR-MMT manufacturing process.

\subsection{Characterizations}

The characteristics of MMT/SR focused on were physical (hardness), mechanical and tribological properties. To confirm the uniform dispersion of the nanofiller, morphology tests, viz., SEM and X-ray diffraction (XRD), were performed. The details of these techniques are summarized in the following paragraphs. 


\subsubsection{Morphology Testing}

XRD was carried out to analyze the maturity and formation of the nanocomposites. XRD analysis was performed in Bruker AXS D8 advance X-ray diffractometer (Bruker India Scientific Pvt Ltd, Mumbai, India) with X-ray source-Cu Karadiation $(\lambda=0.154 \mathrm{~nm})$. The scattering was plotted as a function of scattering angle $2 \theta$.

\subsubsection{Mechanical Testing}

A sample (as shown in Figure 2) preparation and testing for tensile and tear test was performed according to ASTM D 412 and ASTM D624, respectively. The tensile test was performed at a speed of $450 \mathrm{~mm} / \mathrm{min}$. Shore hardness testing was completed according to ASTM D2240. All tests were carried out at a $450 \mathrm{~mm} / \mathrm{min}$ strain rate with an environmental condition of $24{ }^{\circ} \mathrm{C}$ and $54 \%$ humidity.

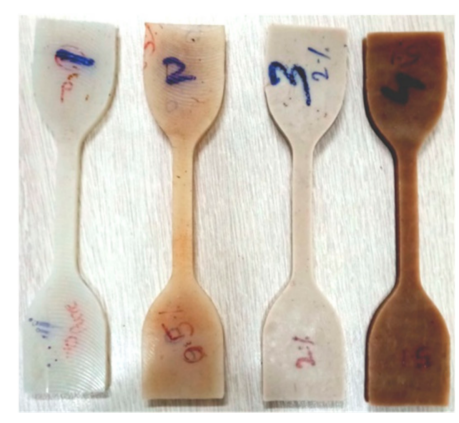

Figure 2. Samples prepared for tensile testing.

\subsubsection{Experimental Design of Tribological Study}

The Schematic representation of pin-on-disc machine and its different components is shown in Figure 3. Levels of control parameters are listed in Table 3. Taguchi's $\mathrm{L}_{16}$ orthogonal array was used to perform the design of tribology experiments, as shown in Table 4.

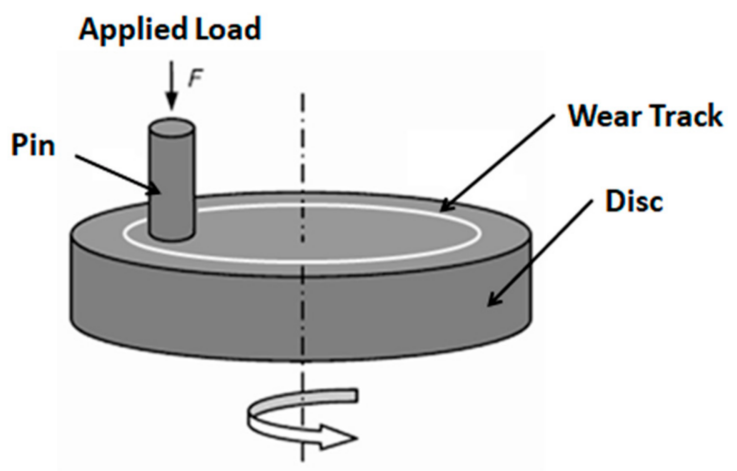

Figure 3. Schematic representation of SR-MMT manufacturing process.

Table 3. Selected levels of different parameters.

\begin{tabular}{ccccc}
\hline Parameter & \multicolumn{4}{c}{ Level } \\
\hline Composition & SR1 & SR2 & SR3 & SR4 \\
\hline Load $(\mathrm{N})$ & 10 & 20 & 30 & 40 \\
Sliding Speed $(\mathrm{m} / \mathrm{s})$ & 1 & 2 & 3 & 4 \\
Sliding Distance $(\mathrm{mm})$ & 1000 & 1800 & 2600 & 3200 \\
\hline
\end{tabular}


Table 4. Taguchi $\mathrm{L}_{16}$ orthogonal array for the design of tribological experiments.

\begin{tabular}{ccccc}
\hline Exp. No. & Composition & Load & Sliding Speed & Sliding Distance \\
\hline 1 & SR1 & 1 & 1 & 1 \\
2 & SR1 & 2 & 2 & 2 \\
3 & SR1 & 3 & 3 & 3 \\
4 & SR1 & 4 & 4 & 4 \\
5 & SR2 & 1 & 2 & 3 \\
6 & SR2 & 2 & 1 & 4 \\
7 & SR2 & 3 & 4 & 1 \\
8 & SR2 & 4 & 3 & 2 \\
9 & SR3 & 1 & 3 & 4 \\
10 & SR3 & 2 & 4 & 3 \\
11 & SR3 & 3 & 1 & 1 \\
12 & SR3 & 4 & 2 & 2 \\
13 & SR4 & 1 & 4 & 4 \\
14 & SR4 & 2 & 3 & 3 \\
15 & SR4 & 3 & 2 & \\
16 & SR4 & 4 & 1 & \\
\hline
\end{tabular}

A pin-on-disc wear testing machine was used, and tests were performed according to the ASTM G99 standard. The samples were cut in the form of a rectangular pin of $10 \times 10 \times$ $30 \mathrm{~mm}$. The rubbing disc was made of EN-31 of hardness $60 \mathrm{HRC}$. All tests were performed at room temperature with general conditions of temperature and humidity. Samples were weighed before and after the experimental runs. An analytical weighing balance was used for accurate measurement of weight loss. The friction force $\left(F_{f}\right)$ recorded by the controller was used for the calculation of friction coefficient $\mu$, as given in Equation (1) below

$$
\mu=\frac{F_{f}}{F_{n}}
$$

where $F_{n}$ is the normal force applied to the specimen.

Also, specific wear rate $(W)$ was calculated by using Equation (2):

$$
W=\frac{\text { Weight Loss }}{\text { Density } \times \text { Normal Load } \times \text { Sliding Distance }}
$$

\subsubsection{SEM and EDS Analysis}

The FESEM analysis was carried out on an ultra-high-resolution FEI Nova NanoSEM 450 machine (FEI, Hillsboro, OR, USA). The machine's resolution is $1.0 \mathrm{~nm}$ at $15 \mathrm{kV}, 1.4 \mathrm{~nm}$ at $1 \mathrm{kV}$, and $1.8 \mathrm{~nm}$ at $3 \mathrm{kV}$ and $30 \mathrm{~Pa}$. EDS spectra were obtained on the same machine with excellent energy resolution ( $123 \mathrm{eV}$ at $\mathrm{Mn} \mathrm{K} \alpha$ and $45 \mathrm{eV}$ at $\mathrm{C} \mathrm{K} \alpha)$, and element detection range from 4 Be to $95 \mathrm{Am}$.

\section{Results and Discussion}

\subsection{X-ray Diffraction Studies}

Figure 4 shows the XRD plot of intensity versus scattering angle for the pure SR, the SR4 composite, and MMT powder samples. MMT powder shows a high degree of crystallinity with a broad peak at $35^{\circ} 2 \theta$ angles. A similar broad reflection is also observed in the SR4 composite, with somewhat lesser intensity, which implies individual MMT particles within the retained crystal structure. The peak corresponding to the SR is at around $30^{\circ}$, which is also observed in the SR4 composite. The existence of these individual constituent peaks in the SR4 composite confirms the correct formation of the composite. 


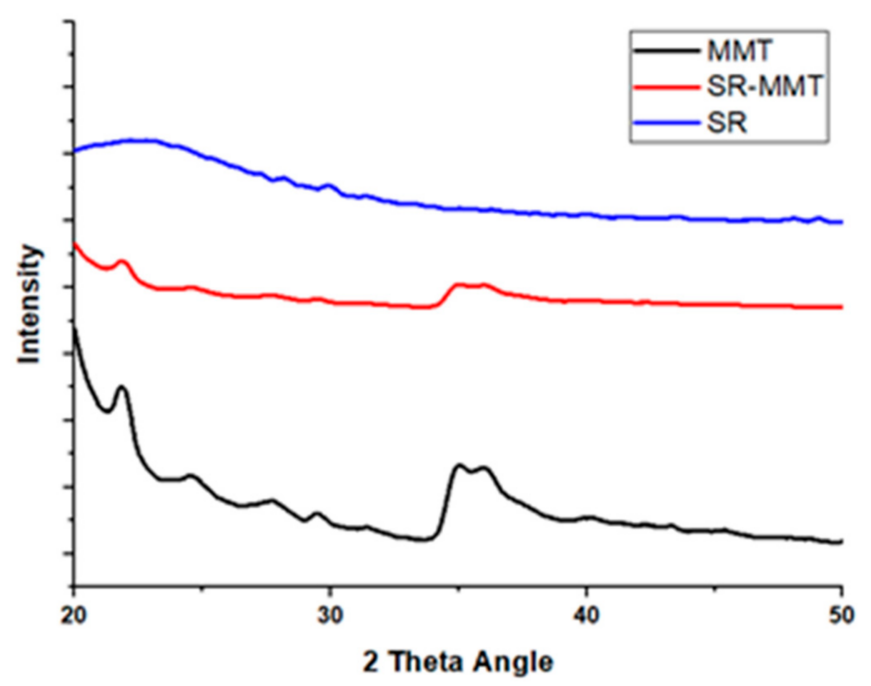

Figure 4. XRD pattern of pure SR, MMT powder and SR4 composition.

\subsection{Mechanical Properties}

\subsubsection{Tensile Strength}

The tensile strength of the SR-MMT nanocomposites is found to increase with an increase in the weight fraction of MMT (Figure 5). The tensile strength of SR1 was observed at $5.39 \mathrm{MPa}$, which increases to 5.66 and $6.02 \mathrm{MPa}$ at SR2 and SR3 compositions, respectively, and then decreases to $5.75 \mathrm{MPa}$ for SR4. The highest value of tensile strength is $6.02 \mathrm{MPa}$ which is $11.68 \%$ higher than the SR1 composition. As seen from the XRD results, the reduced interlayer distance for SR3 composition is the reason behind the increased tensile strength. This reduced interlayer distance improves the interlayer bonding between the matrix and the filler.

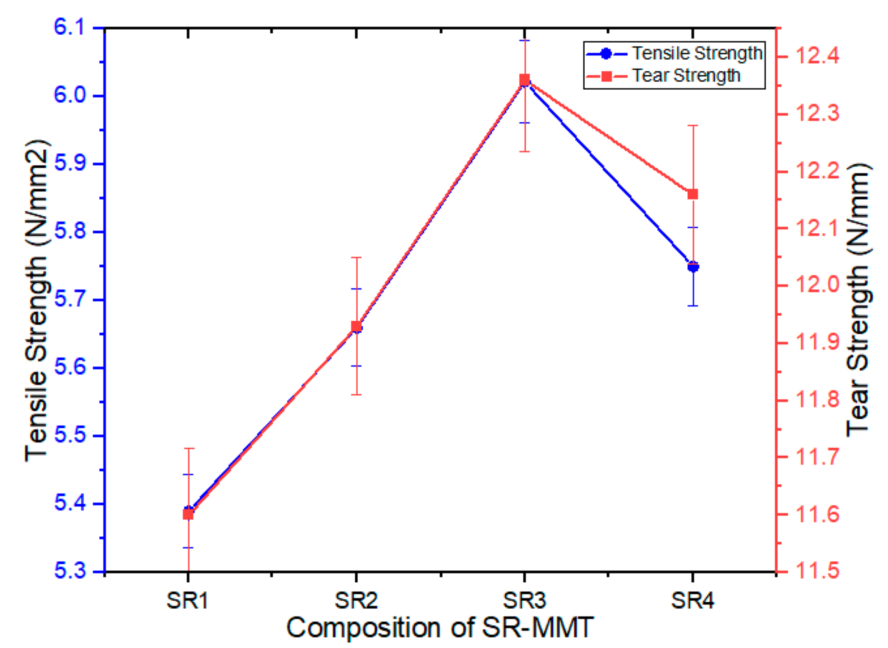

Figure 5. Variation of tensile strength and tear strength of SR-MMT nanocomposites with weight \% of MMT.

\subsubsection{Tear Strength}

The tearing strength is initially found to increase with an increasing amount of MMT. The highest tear strength value is $12.36 \mathrm{MPa}$ for the SR3 composition, $6.55 \%$ higher than for the pure SR. With a further increase in the MMT percentage, the tearing strength starts to decline and reaches $12.15 \mathrm{MPa}$. A better uniform dispersion of the MMT could explain this in the matrix for the SR3 composite. Reduction in the tear strength for the SR4 composition is attributed to the agglomeration in composite with an increase in the wt $\%$ of the MMT. 


\subsubsection{Peak Load, Braking Load, Elongation at Break}

Figure 6 shows the effect of the concentration of the MMT on the peak load and breaking load. It is observed that the load-carrying capacity of the SR3 composition is the highest amongst all of the compositions. The percentage increase in the peak load is $179.71 \%$ as compared to the neat silicon rubber (SR1), and a similar increase is observed in the breaking load. However, with a further increase in the concentration, a reduction in the peak load and a breaking load of $32.4 \%$ is observed. These trends can be attributed to the microstructure and interfacial bonding between the SR and MMT.

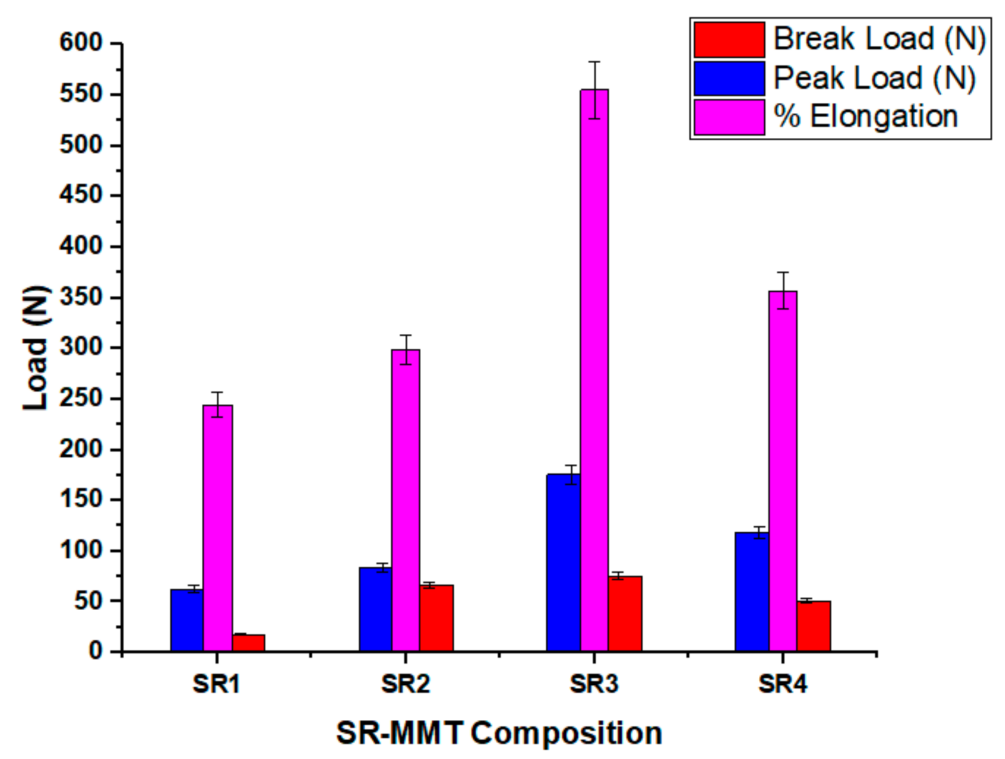

Figure 6. Variation of peak load, break load and \% elongation at break for SR-MMT composition.

\subsubsection{Percentage Elongation at Break}

Figure 6 shows the percentage elongation at break of the SR-MMT nanocomposites for different compositions. The percentage elongation at break increases with an increase in the concentration of the MMT up to a certain percentage. The SR3 composition shows a $56 \%$ higher elongation at break as compared with the SR1 composition. Better interlayer bonding for the SR3 composition resulted in the increased percentage elongation. However, a reduction of $35.6 \%$ is observed with a further increase in the MMT concentration, which can be attributed to the agglomeration of the MMT particles in the matrix. When the loading of the MMT is more than 5\%, clay layers will be less compatible with the SR resulting in the development of a siloxane network [21].

The tensile strength shows a correlation with elongation, i.e., a higher strength for a smaller elongation. The development of a plausible sulfide bond between the backbone chain of the SR and MMT clay improves the degree of cross-linking [22].

\subsubsection{Shore D Hardness}

The relation of hardness with a concentration of the MMT in the SR/MMT nanocomposites is shown in Figure 7. The amount of MMT tends to increase the hardness of the material. The highest shore D hardness of 52 is observed for SR 4 composition. This increase is almost $16 \%$ higher than the SR1 composition. The hardness of the SR can be adjusted by changing the amount of the MMT up to a certain concentration of the MMT. Beyond the SR3 composition, the graph becomes flatter, i.e., the rate at which the hardness increases gets reduced after a certain concentration of the MMT. The increased concentration leads to an agglomeration of the filler causing it to affect not only the mechanical properties, but the mixing process also. Therefore, the optimized amount of the MMT concentration in the SR is $2 \%$ as compared with other configurations under study [8]. 


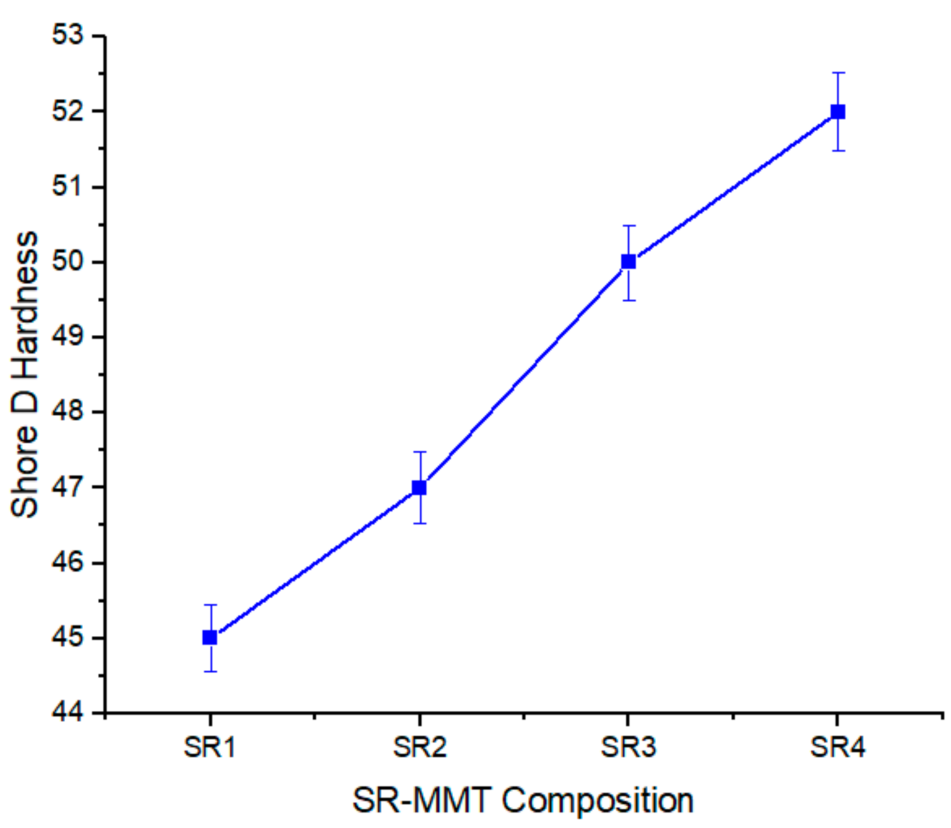

Figure 7. Variation of Shore D hardness for SR/MMT compositions.

\subsubsection{Tensile Fracture Surface Morphology}

The surface morphology of the fractured surface is significant for getting an insight into the interfacial adhesion between the filler and matrix. Figure 8 shows the fracture surface morphology of all four compositions as well as the MMT powder. Figure 8a shows an SEM image of the MMT powder where the MMT particles are visible. Figure $8 \mathrm{~b}$ shows the smooth surface for pure silicon rubber, i.e., the SR1 composition. The SR2 composition shows some cracks after tensile loading. These cracks may be due to inefficient interfacial bonding and surface roughness which act as crack initiation points. The increased MMT content is visible from Figure 8d,e. It is exciting to note that the SR3 composition improves the properties due to increased MMT content and smoother distribution of the MMT particles. A further increase in the percentage of MMT increases the number of voids, resulting in a decrease in the mechanical properties for the SR4 composition. Such reduction confirms the start of agglomeration with the increase in the MMT percentage, leading to the generation of voids.

The interfacial adhesion between the silicon rubber elastomer and MMT nanoclay is responsible for enhancing the tensile and tear properties of the nanocomposites. The uniformly distributed MMT in the silicon rubber matrix creates stress concentration points which absorb energy and help to distribute the load uniformly throughout the matrix as in the case of SR3 composition. Further, it acts as a crack arrester under external loading [12].

\subsection{Tribological Analysis}

\subsubsection{ANOVA Analysis of Friction Coefficient}

ANOVA test results for the COF are listed in Table 5 below. R-Sq (adj) is $76.60 \%$ which represents the significance of the model obtained from experimental observations. The parameter with the highest effect rate load $(55.24 \%)$ and lowest effect rate is sliding speed $(5.65 \%)$. Unaccounted factors in the DOE can be counted as errors, at $11.82 \%$. When the load increases to $40 \mathrm{~N}$, the COF is reduced by $20 \%$ and the lowest COF is for the SR3 composition; after that, the COF increases. So, the loading of the specimen significantly affects the friction coefficient of the material. For SR 3 composition, at $10 \mathrm{~N}$ and $30 \mathrm{~N}$ load, the $\mathrm{COF}$ is 0.710 and 0.340 , respectively, which shows a $52.11 \%$ reduction. 

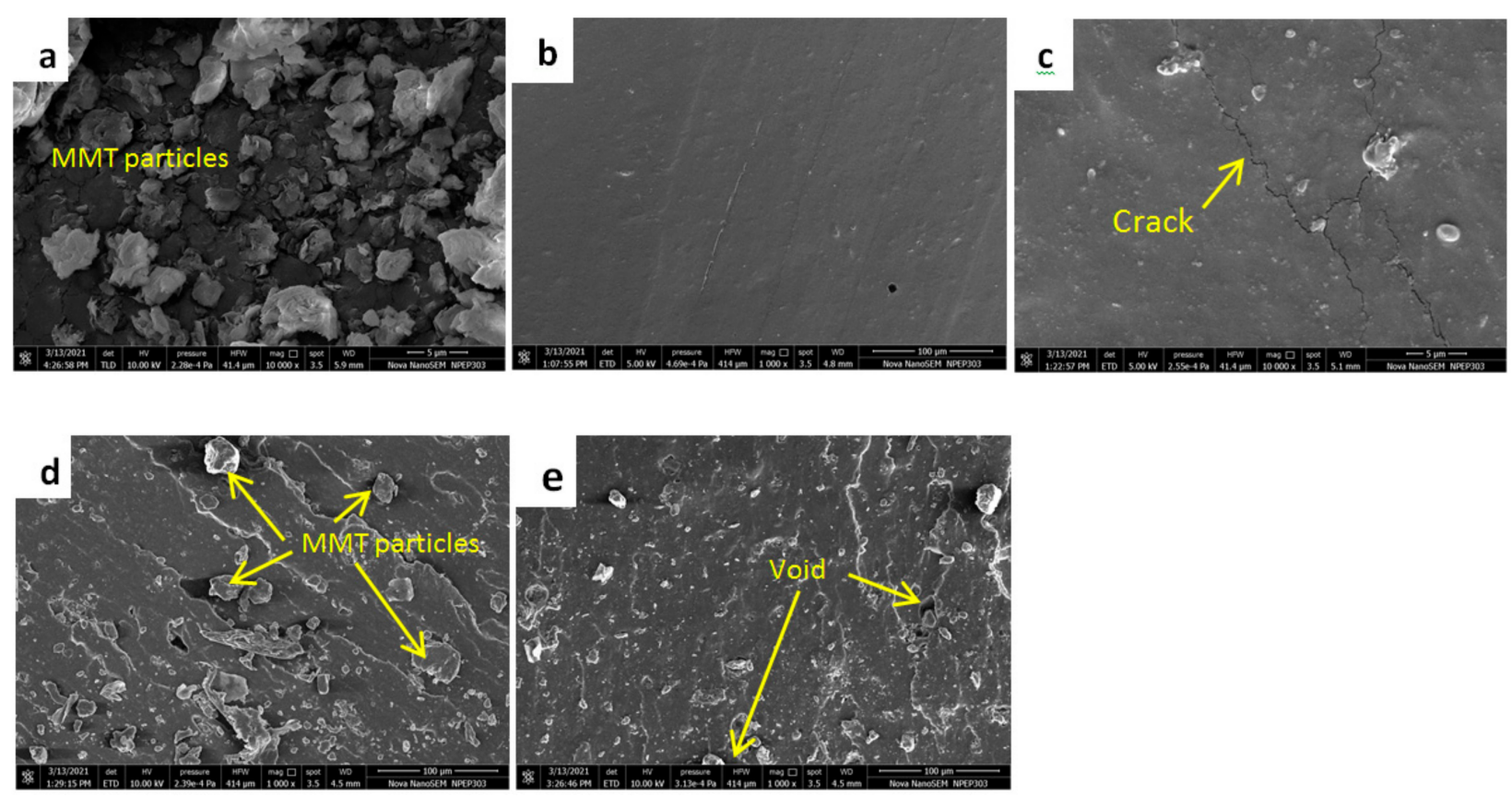

Figure 8. Fracture Surface Morphology for (a) MMT powder (b) SR1 (c) SR2 (d) SR3, and (e) SR4 composition.

Table 5. ANOVA for Coefficient of friction.

\begin{tabular}{ccccccc}
\hline Source & DF & $\begin{array}{c}\text { Sum of } \\
\text { Squares } \\
\text { (SS) }\end{array}$ & $\begin{array}{c}\text { Mean } \\
\text { Square } \\
\text { (MS) }\end{array}$ & F-Value & $p$-Value & $\begin{array}{c}\text { Effect } \\
\text { Rate (\%) }\end{array}$ \\
\hline $\begin{array}{c}\text { Composition } \\
(\%)\end{array}$ & 1 & 0.08102 & 0.08102 & 2 & 0.185 & 6.59 \\
$\begin{array}{c}\text { Load (N) } \\
\text { Sliding Speed } \\
(\mathrm{m} / \mathrm{s})\end{array}$ & 1 & 0.67881 & 0.37881 & 9.36 & 0.011 & 55.24 \\
$\quad 1$ & 0.06949 & 0.06949 & 1.72 & 0.217 & 5.65 \\
$\begin{array}{c}\text { Sliding } \\
\text { Distance (mm) } \\
\text { Error }\end{array}$ & 1 & 0.25437 & 0.25437 & 6.28 & 0.029 & 20.70 \\
$\quad 11$ & 0.14525 & 0.04048 & & & 11.82 \\
\hline Total & 15 & 1.22894 & & & & 100.00 \\
\hline Significance & R-sq = $80.95 \%$ & & R-sq (adj) $=76.60 \%$ & \\
\hline
\end{tabular}

\subsubsection{ANOVA Analysis of Weight Loss}

ANOVA test results for weight loss are listed in Table 6 below. The R-Sq (adj) value is $84.12 \%$, representing the significance of the model obtained from experimental observations. The highest effect rate for the filler loading is $55.19 \%$, which significantly influences the weight loss of the material. The theory of plasticity can explain the increase in the weight loss due to an increase in the filler loading. As the content of the filler increases, the stress level also increases, which results in weight. The second significant influencing parameter is the sliding distance which has an effective rate of $27.55 \%$. Unaccounted factors in the DOE can be counted as errors, at $5.43 \%$.

\subsubsection{ANOVA Analysis of Specific Wear Rate}

ANOVA test results for specific wear rate are listed in Table 7. R-Sq (adj) value is $71.43 \%$, representing the significance of the model obtained from experimental observations. The wear rate is influenced more by the sliding distance with an effective rate of $51.08 \%$. The second largest influencing parameter is the filler content, with a rate effect of $34.95 \%$. The specific wear rate is found to reduce with an increase in the sliding distance. The specific wear rates of SR1 at different sliding distance levels, viz., 1, 2, 
3, and 4, are $2.58 \times 10^{-7} \mathrm{~cm}^{3} / \mathrm{N}-\mathrm{m}, 2.37 \times 10^{-7} \mathrm{~cm}^{3} / \mathrm{N}-\mathrm{m}, 1.86 \times 10^{-7} \mathrm{~cm}^{3} / \mathrm{N}-\mathrm{m}$, and $8.93 \times 10^{-8} \mathrm{~cm}^{3} / \mathrm{N}-\mathrm{m}$, respectively. With an increase in the MMT concentration, the wear rate is reduced drastically from $41 \%$ to $60 \%$, corresponding to different sliding distance levels for the SR3 composition. Initially, when the rubber surface is in contact with the steel, heat is generated at a higher rate. This exposes the MMT nanofiller to sliding, resulting in a thin film (transfer film) formation on the contact surface and a reducing of the wear rate [23].

Table 6. ANOVA for Weight Loss.

\begin{tabular}{ccccccc}
\hline Source & DF & $\begin{array}{c}\text { Sum of } \\
\text { Squares } \\
\text { (SS) }\end{array}$ & $\begin{array}{c}\text { Mean } \\
\text { Square } \\
\text { (MS) }\end{array}$ & F-Value & $p$-Value & $\begin{array}{c}\text { Effect } \\
\text { Rate (\%) }\end{array}$ \\
\hline $\begin{array}{c}\text { Composition } \\
(\%)\end{array}$ & 1 & 0.000434 & 0.000434 & 1.64 & 0.226 & 8.11 \\
$\begin{array}{c}\text { Load (N) } \\
\text { Sliding Speed } \\
(\mathrm{m} / \mathrm{s})\end{array}$ & 1 & 0.002953 & 0.000343 & 1.3 & 0.278 & 55.19 \\
$\quad 1$ & 0.000199 & 0.000199 & 0.75 & 0.404 & 3.72 \\
$\begin{array}{c}\text { Sliding } \\
\text { Distance (mm) } \\
\text { Error } \\
\text { Total }\end{array}$ & 1 & 0.001474 & 0.001474 & 5.58 & 0.038 & 27.55 \\
\hline Significance & 11 & 0.000291 & 0.000264 & & & 5.43 \\
\hline
\end{tabular}

Table 7. ANOVA for specific wear rate.

\begin{tabular}{ccccccc}
\hline Source & DF & $\begin{array}{c}\text { Sum of } \\
\text { Squares (SS) }\end{array}$ & $\begin{array}{c}\text { Mean } \\
\text { Square } \\
\text { (MS) }\end{array}$ & F-Value & $p$-Value & $\begin{array}{c}\text { Effect } \\
\text { Rate (\%) }\end{array}$ \\
\hline $\begin{array}{c}\text { Composition } \\
(\%)\end{array}$ & 1 & $7 \times 10^{-6}$ & 0.000007 & 1.54 & 0.241 & 7.53 \\
$\begin{array}{c}\text { Load (N) } \\
\text { Sliding Speed } \\
(\mathrm{m} / \mathrm{s})\end{array}$ & 1 & $3.25 \times 10^{-5}$ & 0.00001 & 2.09 & 0.176 & 34.95 \\
$\begin{array}{c}\text { Sliding } \\
\text { Distance (mm) } \\
\text { Error }\end{array}$ & 1 & $1 \times 10^{-6}$ & 0.000001 & 0.19 & 0.67 & 1.08 \\
$\quad 11$ & $5.75 \times 10^{-5}$ & 0.000025 & 5.37 & 0.041 & 51.08 \\
\hline Total & 15 & $93 \times 10^{-6}$ & 0.000005 & & & 5.38 \\
\hline Significance & \multicolumn{2}{c}{$\mathrm{R}$-sq $=83.04 \%$} & & & 100.00 \\
\hline
\end{tabular}

\subsubsection{Influence of Normal Load and Sliding Velocity}

Changes in the COF and specific wear rate by changing the load applied and sliding velocity are shown in Figure $9 \mathrm{a}-\mathrm{d}$. At $10 \mathrm{~N}$ loading, the COF reduces by almost $25 \%$, from 0.950 to 0.710 , for the SR3 composition compared with the SR1 composition. At the same time, a $60 \%$ reduction of the wear rate is observed at $10 \mathrm{~N}$ loading for the SR3 composition as compared to the SR1 composition. The COF and wear rate are the highest for a load of $10 \mathrm{~N}$. Interfacial adhesion is so strong that lower loading cannot break the bond between the constituent elements. Due to this, the material does not break into chips and friction between the surfaces increases. However, for $40 \mathrm{~N}$ loading, a dramatic behaviour is observed where the COF reduces, and the specific wear rate increases against the trend due to an increase in the MMT concentration. 

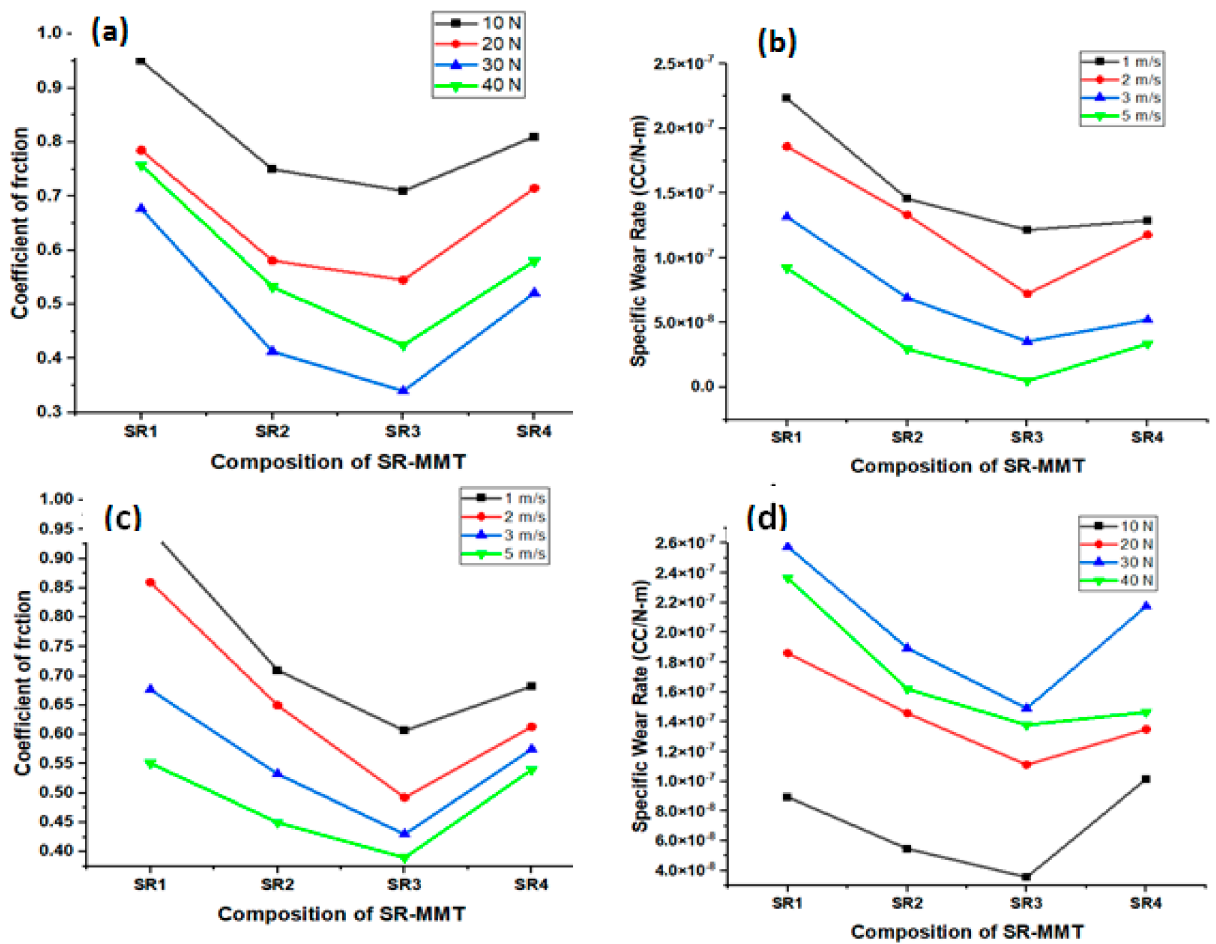

Figure 9. Variation of (a) Coefficient of friction (COF), (b) Specific wear rate for all compositions at different loads, and (c) Coefficient of friction (COF) (d) Specific wear rate for all compositions at a different sliding velocity.

With an increase in the MMT content and the sliding velocity, the COF and specific wear rates decrease. For the SR3 composition, the lowest COF and wear rate is observed. When the applied load increases to $30 \mathrm{~N}$, a significant reduction in the COF by $52.11 \%$ is observed in the SR3 composition. After $30 \mathrm{~N}$ the COF is found to increase by $20 \%$ to 0.425 . When the sliding velocity is lower, more surface-to-surface contact with the friction plate is experienced, resulting in an increasing COF and wear rate. The lubricant film formed between the contacting surfaces is due to the wearing down of polymeric material [24,25]. The transfer layer prevents direct contact between the rubbing surfaces. Generation of the transfer film is another reason for the reduction in the COF as the concentration of the MMT increases. Also, it is evident from the experimental investigation that the SR3 composite shows superior tribological performance for the COF and wear compared to other compositions.

\subsubsection{Worn Surface Morphology under Dry Sliding}

SEM images shown in Figure 10 of worn surfaces throw more light on the wear behaviour of the SR and nanocomposites under pin-on-disc wear testing under dry sliding. The rubber material is subjected to two types of friction mechanisms; one is hysteresis, and the other is adhesive friction [26,27]. The rubber specimen tends to deform, causing energy loss due to hysteresis friction.

The surface of the sample and disc advances the adhesive friction. The images are taken for samples and tested at a sliding velocity of $5 \mathrm{~m} / \mathrm{s}$ and normal loading of $40 \mathrm{~N}$. Pure silicon rubber (SR1) has poor mechanical strength. Hence, it is susceptible to adhesive friction, as shown in Figure 10a. For the SR4 composition, the MMT particles are found to chip off. The particles getting chipped off from the surface form a lubricating film (transfer film) between the disc and specimen surface. The transfer film decreases the adhesive wear, as seen in the SR1 composition. For the SR3 composition, the MMT particles are responsible for reducing the friction due to a reduction in the contact area. Poor bonding between the filler and the matrix leads to chipping of the filler from the matrix which reduces the 
adhesive friction component. For $5 \mathrm{wt} \%$ of the MMT, localized material removal is seen in the SEM imaging.
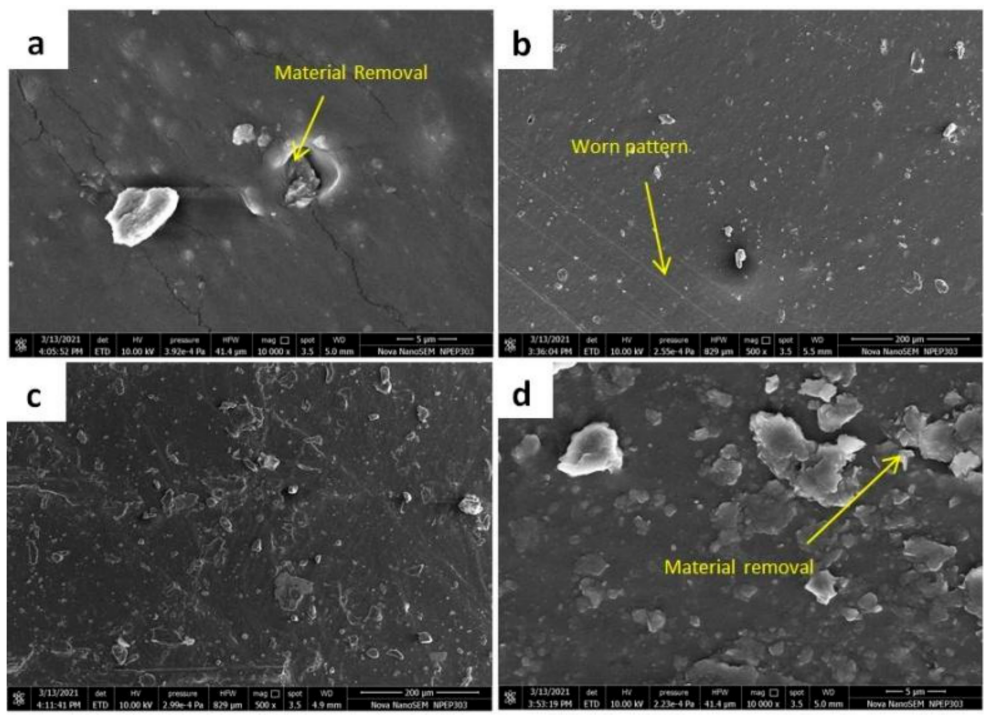

Figure 10. Worn Surface Morphology for (a) SR1 (b) SR2 (c) SR3 and (d) SR4 composition after wear test for a load of $40 \mathrm{~N}$ and sliding speed of $5 \mathrm{~m} / \mathrm{s}$.

Adding the MMT beyond the optimum ( $2 \mathrm{wt} \%$ ) affects the lubricating film formation due to MMT agglomeration. This agglomeration leads to localized adhesive junctions, increasing both types of friction mechanisms [12]. From the SEM analysis it can be understood that adhesive wear is the leading mechanism of wear. The rubber deforms and glues under the applied load under dry sliding conditions. These glued junctions chip off due to the sliding action. Therefore, the friction initiated by forming the glued junctions is sheared off leading to the removal of the MMT particles and lubricant film formation, resulting in adhesive wear [28].

\subsubsection{EDS Spectrum of the Worn Surface}

Chemical elements on the worn surface can be seen in the EDS spectrums shown in Figure 11. Silicium, carbon, and oxygen are detected for the worn surface under dry sliding conditions. Also, the weight percent of $\mathrm{O}$ and $\mathrm{C}$ elements found in the SR1 composition are 17.33 and 15.07, respectively, whereas for the SR3 composition they are 15.21 and 17.71 . The increased count of the O element and the reduced count of the C element for the SR1 composition indicates more thermal depolymerization than the SR3 composition. Similar elements are available in the pure silicon rubber, which leads to the conclusion that there is no chemical reaction that happened due to the wearing of the specimens.
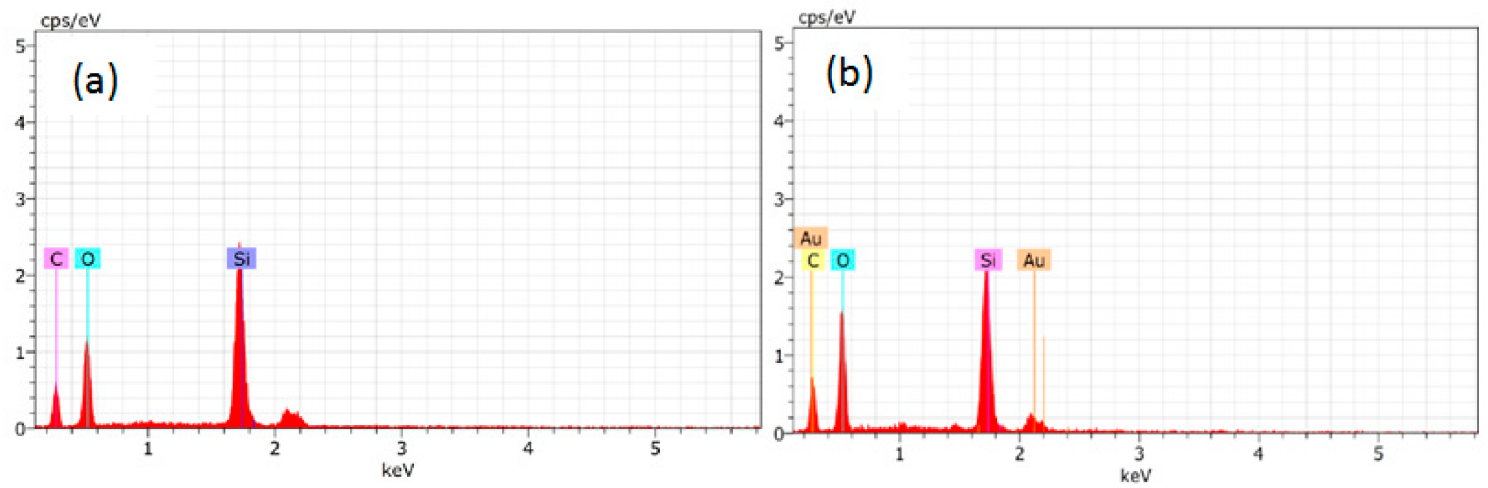

Figure 11. EDS Spectra for (a) SR1 and (b) SR3 composition after wear test. 


\section{Conclusions}

A new silicon rubber/MMT nanocomposite was efficaciously fabricated. When explored for mechanical and tribological performance, the MMT-SR nanocomposite exhibited outstanding properties that suit varied applications in the automotive and other fields. Besides, vital tribological parameters like load, sliding speed, and sliding distance were studied using ANOVA. FESEM and EDS analysis of the fractured and worn surfaces was also performed. Following are a few key observations to summarize:

- The SR-MMT nanocomposite with $2 \%$ exhibited the highest tensile and tear strength. Compared to SR1, the SR3 composition showed almost $10 \%$ and $6 \%$ improvement in tensile and tear strength.

- Hardness showed continuous improvement with an increase in the MMT percentage.

- The tribological experiments and its ANOVA revealed that the load has more influence on the friction coefficient while the sliding velocity influences the wear rate.

- A reducing trend of the specific wear rate and the COF was found up to the SR3 composition, and after that, it increased for the SR4 composition. Also, with an increase in the loading, the COF increased but the wear rate decreased. The increasing trend is observed for both the COF and the wear rate, increasing the sliding velocity.

- The surface morphology of different configurations obtained by FE-SEM justifies the results obtained from the mechanical and tribological experiments. The smoother and uniform distribution of the MMT can be observed for the SR3 composition.

- The adhesive wear mechanism is the leading mechanism of wear observed for the developed nanocomposite.

The above conclusion favors the developed nanocomposite from the fundamental analysis and can be confidently used in the automotive field and other suitable applications.

Author Contributions: Conceptualization, I.S., Y.M. and F.M.; Data curation, A.S.; Funding acquisition, M.T.H.S. and A.U.M.S.; Methodology, I.S.; Project administration, Y.M.; Supervision, I.S. and V.D.; Writing—original draft, A.S.; Writing—review and editing, I.S., Y.M. and M.T.H.S. All authors have read and agreed to the published version of the manuscript.

Funding: Universiti Putra Malaysia funded this research, grant number GPB 9668200 and Ministry of Education Malaysia, grant number FRGS/1/2019/STG07/UPM/02/2. Universiti Putra Malaysia funded the APC.

Data Availability Statement: The data presented in this study are available on request from the corresponding author.

Acknowledgments: The authors would like to thank Universiti Putra Malaysia for the financial support through Geran Putra Berimpak, GPB 9668200 and supported by the Ministry of Education Malaysia (MOE) through the Fundamental Research Grant Scheme (FRGS/1/2019/STG07/UPM/02/2). The authors would also like to thank the Department of Aerospace Engineering, Faculty of Engineering, Universiti Putra Malaysia and Laboratory of Biocomposite Technology, Institute of Tropical Forestry and Forest Product (INTROP), Universiti Putra Malaysia (HICOE) for the close collaboration in this research.

Conflicts of Interest: The authors declare no conflict of interest.

\section{References}

1. Dong, Y.; Ke, Y.; Zheng, Z.; Yang, H.; Yao, X. Effect of stress relaxation on sealing performance of the fabric rubber seal. Compos. Sci. Technol. 2017, 151, 291-301. [CrossRef]

2. Xu, R.; Luo, G.; Xia, H.; He, W.; Zhao, J.; Liu, B.; Tan, J.; Zhou, J.; Liu, D.; Wang, Y.; et al. Novel bilayer wound dressing composed of silicone rubber with particular micropores enhanced wound re-epithelialization and contraction. Biomaterials 2015, 40, 1-11. [CrossRef] [PubMed]

3. Kumar, V.; Lee, G.; Singh, K.; Choi, J.; Lee, D.-J. Structure-property relationship in silicone rubber nanocomposites reinforced with carbon nanomaterials for sensors and actuators. Sens. Actuators A Phys. 2020, 303, 111712. [CrossRef]

4. Han, R.; Quan, X.; Shao, Y.; Niu, K. Tribological properties of phenyl-silicone rubber composites with nano-CeO ${ }_{2}$ and graphene under thermal-oxidative aging. Appl. Nanosci. 2020, 10, 2129-2138. [CrossRef] 
5. Li, W.; Gedde, U.W.; Hillborg, H. Structure and electrical properties of silicone rubber filled with thermally reduced graphene oxide. IEEE Trans. Dielectr. Electr. Insul. 2016, 23, 1156-1163. [CrossRef]

6. Li, H.; Tao, S.; Huang, Y.; Su, Z.; Zheng, J. The improved thermal oxidative stability of silicone rubber by using iron oxide and carbon nanotubes as thermal resistant additives. Compos. Sci. Technol. 2013, 76, 52-60. [CrossRef]

7. Anyszka, R.; Strzelecki, D. Tribology in Industry Tribological Properties of Silicone Rubber-Based Ceramizable Composites Destined for Wire Covers. Part I. Studies of Block-On-Ring Friction Contact. Tribiology Ind. 2015, 37, 154-160.

8. He, Q.; Li, A.; Zhang, Y.; Liu, S.; Guo, Y.; Kong, L. A study on mechanical and tribological properties of silicone rubber reinforced with white carbon black. Tribol. Mater. Surf. Interfaces 2018, 12, 9-16. [CrossRef]

9. Malas, A.; Pal, P.; Das, C.K. Effect of expanded graphite and modified graphite flakes on the physical and thermo-mechanical properties of styrene butadiene rubber/polybutadiene rubber (SBR/BR) blends. Mater. Des. 2014, 55, 664-673. [CrossRef]

10. Ke, Y.; Yao, X.; Yang, H.; Liu, X. Kinetic friction characterizations of the tubular rubber seals. Tribol. Int. 2014, 72, 35-41. [CrossRef]

11. Pal, K.; Das, T.; Rajasekar, R.; Pal, S.K.; Das, C.K. Wear Characteristics of Styrene Butadiene Rubber/Natural Rubber Blends with Varying Carbon Blacks by DIN Abrader and Mining Rock Surfaces. Appl. Polym. Sci. 2009, 111, 348-357. [CrossRef]

12. Sarath, P.; Samson, S.V.; Reghunath, R.; Pandey, M.K.; Haponiuk, J.T.; Thomas, S.; George, S.C. Fabrication of exfoliated graphite reinforced silicone rubber composites-Mechanical, tribological and dielectric properties. Polym. Test. 2020, 89, 106601. [CrossRef]

13. Sanchez-Hidalgo, R.; Blanco, C.; Menendez, R.; Verdejo, R.; Lopez-Manchado, M.A. Multifunctional Silicone Rubber Nanocomposites by Controlling the Structure and Morphology of Graphene Material. Polymers 2019, 11, 449. [CrossRef]

14. Zheng, Z.; Yang, H.; Yao, X. Wear-Resistant Graphene-Silicone Rubber Composites. Tribol. Trans. 2019, 63, 205-214. [CrossRef]

15. Cheraghian, G. Synthesis and properties of polyacrylamide by nanoparticles, effect nanoclay on stability polyacrylamide solution. Micro Nano Lett. 2017, 12, 40-44. [CrossRef]

16. Ha, S.-R.; Rhee, K.-Y.; Shin, H. Effect of MMT concentration on tribological behavior of MMT/Epoxy nanocomposite. J. Nanosci. Nanotechnol. 2008, 8, 4869-4872. [CrossRef]

17. Yan, S.; Xue, Y.; Hu, Y.; Wang, S. Thermal, mechanical, and tribological properties of sodium-montmorillonite-nanoparticlereinforced polyethersulfone and polytetrafluoroethylene ternary composites. Friction 2019, 1-18. [CrossRef]

18. Ma, Y.; Zhao, Z.; Xian, Y.; Wan, H.; Ye, Y.; Chen, L.; Zhou, H.; Chen, J. Highly Dispersed Ag2S Nanoparticles: In Situ Synthesis, Size Control, and Modification to Mechanical and Tribological Properties towards Nanocomposite Coatings. Nanomaterials 2019, 9, 1308. [CrossRef]

19. Kazemi-Khasragh, E.; Bahari-Sambran, F.; Platzer, C.; Eslami-Farsani, R. The synergistic effect of graphene nanoplateletsmontmorillonite hybrid system on tribological behavior of epoxy-based nanocomposites. Tribol. Int. 2020, 151, 106472. [CrossRef]

20. Smirnov, A.; Peretyagin, P.; Pinargote, N.W.S.; Gershman, I.; Bartolomé, J.F. Wear Behavior of Graphene-Reinforced AluminaSilicon Carbide Whisker Nanocomposite. Nanomaterials 2019, 9, 151. [CrossRef]

21. Perera, S.J.; Egodage, S.M.; Walpalage, S. Enhancement of mechanical properties of natural rubber-clay nanocomposites through incorporation of silanated organoclay into natural rubber latex. e-Polymers 2020, 20, 144-153. [CrossRef]

22. Yang, Z.; Peng, H.; Wang, W.; Liu, T. Crystallization behavior of poly(E-caprolactone)/layered double hydroxide nanocomposites. J. Appl. Polym. Sci. 2010, 116, 2658-2667. [CrossRef]

23. Chen, C.; Zhang, Z.; Zhao, X.; Ye, L. Polyoxymethylene/graphene oxide-perfluoropolyether nano-composite with ultra-low friction coefficient fabricated by formation of superior interfacial tribofilm. Compos. Part A Appl. Sci. Manuf. 2020, $132,105856$. [CrossRef]

24. Bahadur, S.; Sunkara, C. Effect of transfer film structure, composition and bonding on the tribological behavior of polyphenylene sulfide filled with nano particles of $\mathrm{TiO}_{2}, \mathrm{ZnO}, \mathrm{CuO}$ and $\mathrm{SiC}$. Wear 2005, 258, 1411-1421. [CrossRef]

25. Schwartz, C.J.; Bahadur, S. Studies on the tribological behavior and transfer film-Counterface bond strength for polyphenylene sulfide filled with nanoscale alumina particles. Wear 2000, 237, 261-273. [CrossRef]

26. Tabor, D. Hysteresis Losses in the Friction of Lubricated Rubber. Rubber Chem. Technol. 1960, 33, 142-150. [CrossRef]

27. Greenwood, J.A.; Tabor, D. The Friction of Hard Sliders on Lubricated Rubber: The Importance of Deformation Losses. Proc. Phys. Soc. 1958, 71, 989-1001. [CrossRef]

28. Suresha, B.; Kumar, B.R.; Venkataramareddy, M.; Jayaraju, T. Role of micro/nano fillers on mechanical and tribological properties of polyamide66/polypropylene composites. Mater. Des. 2010, 31, 1993-2000. [CrossRef] 